\title{
LOCAL AREA GIGABIT NETWORKING
}

\author{
Don E. Tolmie \\ Los Alamos National Laboralory \\ Los Alamos, New Mexico
}

\begin{abstract}
Computer networks must become faster as the equipment that is being incerconnected increases in power and performance. Ethemet, with a $10 \mathrm{Mbit} / \mathrm{s}$ speed, seemed awesome a few years ago, but is beginning to show its age as more machines are tied together, and workstations anain the power of yesterdays mainframes.

Networks using gigabit speeds are just starting to become available and offer a whole new set of problems and potential. This paper addresses what the higher speeds are being used for. the "standands" efforts specifying the higher speed channels, the netwnik architectures being proposed. and some of the open problems requiring extensive further work.
\end{abstract}

\section{WHY DO WE NEED GIGABIT NETWORKS}

Why n networks were mainly used to carry key strokes between dumb terminals and mainframes, 9600 baud was quite adequate; it was considembly faster then people could read. Toda! it is more common to pass files and pictures hetween the workstations. mainframes, and storage systens. The emphasis is on improving the users productivity and avoiding network botdenecks.

\section{Visualization}

If a picture is worth a thousand words, then remember that II probably also takes a thousand times ile bandwiuth to trunsfer that peture. People are not content with just pictures. presentang itre computer output data in movie lommat (called visualization) is the newest ctove axd offers -ven lipher user productivity intereases. The potentid haid width of the human eye-hrain system has been calculated lo be on ile order of a tew pigalits per second III. Inence pigatsit spoeds stould salisfy uxe undividual uscr's icedis for a whule.

J11e l.os Alamos Natomal l.aloosalory is operated by the

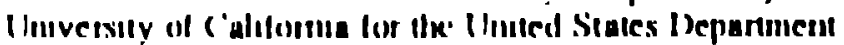
"I I:neigy under comliace W. 7Alls lieNci 36. This work was peiformed under ausplices of tle II.S. Ixpartment of Idrikgy
The networking factors of importance for visualization are raw speed and non-interference berween data streams - if a visualization daca stream is interrupted by another packet. then the user sees a glitch which is very distracting.

Visualization sessions also tend to last for many seconds, compared to a single packet transfer which may only take a few microseconds. Error control is also unique in that data in ermr is omitted rather than being retransmitted.

\section{File Transfers}

As the computers become faster, they also increase their appetite for data. A computer that is constipated b:cause of bottlenectes for Input or output dau is wasting useful compute cycles. A major factor is the bandwidth between the computer and its mass stornge sysiem. Mass stomge sysums used to be limited to single disks attached intimately to individual computer systems; loday the urend is for groups of disks to be shared among a group of isctworked workstations.

Not only are the disk systems becoming faster by taking advantage of rechniques such as stripping, but the network interconnects must also be faster, e.8. FDDI [2] at 100 Mbit/s. The networking factors of importunce for file trassfers are raw spoed and fairly large files: latency and intc. fering data streams are not major concerns.

\section{Remote procedure calls}

An itteresting concept that is gaining acceptance is the cluse coupling of many workstations to achieve the compute power of a supercomputer. Single (.PU) supercomputers are nuning out of potenual pertonmaike pains due to the laws of physics limiting the speed of liphit and electrons. P'erfomanc' gains in the future will Ix achieved by interioruxecting many smaller computers and spreading lle problem across all of them. This has Ireen termed "lle allack of the killer micrus", "11re iclworking fattors of impoituke for remone proxedure calls (KPC "s) are iaw spred. low cost (it shouldu't coss more than ile workstation), atul low latency. ilie

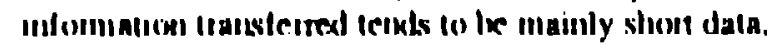
conitul, nixl svitchomising paikets. 


\section{STANDARDS}

The cumputing industry has become aware that hardware and software standards are necessary for future growth No single company can provide all of the solutions, and interoperation with other vendors requires agreed upon interfaces. The users are also cemanding conformance to standards so that they can purihase from multiple vendors, and minimize the r training costs.

Some years ago some people thought that standards stifled creativity. Il is our observation that standards allow a company in invest a larger amount in their own areas of special experise, with a smaller investment required to interface to multiple other vendors that conform to the standard. Otherwise, the cost of scparate interfaces to each vendor may wel! outweigh the cost of the main business.

We have also seen that the standards process usually brings logether the best and brightest people of many comparies to work collectively on a problem. Design by comminec really does work: the output of a standards committee is usually considerably more thorough and of higter quality than if one person or one company had done the complete jcb. We cannot say enough good things abo ' the companies and individuals that suppor: the volunkers

In the gigabit computer networking arena, the HighPerformance Parallel Interface (HUPPI) [3] [4] and Fibre Channel (FC) (5) are examples of interfaces currendy in the standards proc sss. Synchronous Optical Nerwork (SONET) is an example of standardization of higler speids in the uelecom industry. Protocol and sofiware standards have also berxefited from conmilice input.

\section{III;I.PERFORMANC:; PARALI.FI. INTFKFAC', (IIIPPI)}

Ihe IIUP' effor was started by the IAs Alanos National i alooratory in carly 198\%. (Jur motivation was to have the vendots ull the superomputer communty agree on a physical interface standanl so that separate unterface udipters would nex le regured lo comect io cach veixlor's popmetary interface. When we lonk our proposal for an

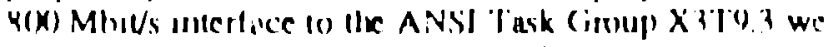

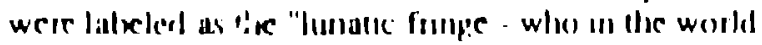

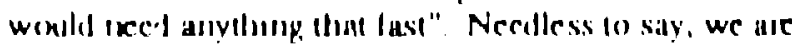

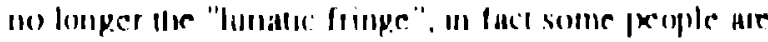
savilip. Llat we ammed loo luw

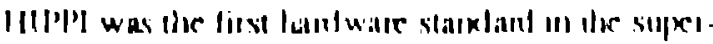

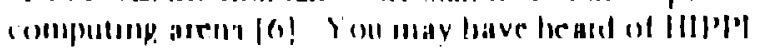

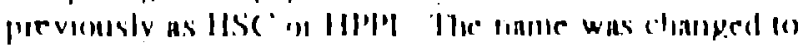

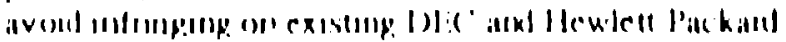

trademarks. Some of the initial X3T9.3 goals for HIPPI included:

- a fire hose for moving data at 800 or $1600 \mathrm{Mbit} / \mathrm{s}$,

- get it done quickly since we had immediate needs,

- use current technology, i.e., no new silicon required,

- avoid options, and

- keep it simple.

We achieved these goals, and the first HIPPI interfaces were delivered in late 1988. Since then many vendors have implemented HDPPI on their products, or are in the process of implementing HIPPI. Currently HIPPI is the interface of choice in the supercomputing arena [7].

HIPPI provides a point-to-point simplex data path; that is, it transfers in one direction only. Two back-to-back HIPPIs provide full duplex or dual simplex operation. $800 \mathrm{Mbit} / \mathrm{s}$ is supponed on one cable, $1600 \mathrm{Mbit} / \mathrm{s}$ requires two cables. The cables use twisted-pairs copper wires. are limited to 25 meters in length, and are abo'st $1 / 2$ inch in diameter. Standard ECL drivers and receivers are used.

The hierarchy within HLPPI is:

- Connection - must exist before dala can be iransferred

- Packer - Groups muluple bursts togedher into a logica! entity

- Burst - Up to I or 2 KBytes, basic now contro. unit, words within a burst are transferred synchronously with a $25 \mathrm{MHz}$ clock, a checksum follows cach burst

- Words - 32 bits on $800 \mathrm{Mbi} / \mathrm{s}$ HIPPI. 64 bits on $1600 \mathrm{Mhi} / \mathrm{s}$ HIPPI, additional parity hils for each byle in cach word

IIIPPI also provides a flow control mechanism that allows full bandwidth over many kilomecers - for use with filer optic exterders or across other networks such as SONET. How control is dorke on 1 KByic or 2 KByic bursts, decreasing the physical level overicad. I:rror detection is done in a modular fashion on individual hyles and bursts; supponing very large (negabyte) packets in a consistent fushion. Eirror recovery is the responsibility of higher layer protocols.

Necworking. al the pliysical luyer is supported by IIIl'l'l ackerssing and "conisection" constructs. A common IIIPl'l inetwork architecliure uses h clussbar type circull swilch. for exumnle a Network Systems (ouporalion l'SK Ilub. It works much like your nomal iclephore comecton. That is, the litply source povides a

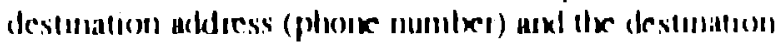

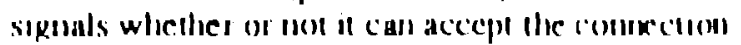
(allswers the phone or hangs up) (Dnce a consectlon is maxle, Imuleiple packets of dala may Ir passed willoul

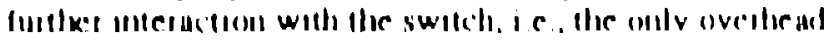

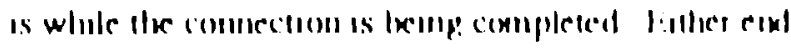
may hamp. up, Hemmumb! the connectum 
The suile of HIPPI documents has expanded bevond the physical layer (HIPPI-PH) described above. HIPPI-SC (Switch Control) defines how physical layer switches operate and are addressed. The HIPPI-FP (Framing Protocol) operates much like a data link layer, breaking large packets up into smaller bursts for transfer across HIPPI-PH, and providing a header describing who the packet belongs to and where the data is located in the packet.

Multiple protocols are suppored above HIPPI-FP. HIPPI-LE (802.2 Link Encapsulation) provides a mapping to the IEEE 802.2 data link for suppon of common network protocols such as TCP/IP. HIPPI-MI (Memory Interface) provides commands for reading and writing memory systems atached via HIPPI. A mapping to the Intelligent Peripheral Interface (IPI-3) command sets for disks and tapes is also supported, and is currently heing used for stripped disk products.

This paper was written in May 1991. but the status of the HIPPI documents in September of 1991 should be about as lollows.

- HIPPI-PH - an approved ANSI standard

- HIPPI-FP - in public review

- HIPPI-LE - in public review

- HIPPI-MI - just startine the review cvele

- HIPPI-SC - just starting the review cycle The mapping to IPI-3 will probably be done as revisions to the existing [PI-3 standards rather than a separate HIPPI document. These revisions would also include mappings to Fibre Channel. The HIPPI-PH document has been submitted to ISO. the intemational standards orgarization, and the other HIPI' documents will be subnutted when siey are lurther along.

\section{FIBRE, (IIANNEL (FC)}

(Yes the name is spelled conectly - the documents will be submitted as inte riational standards, and intemationally the spellung is "libre".)

When the stankdardization eflon for IIIPPI staned in 1987. ANSI I ask (iroup $\times 379.3 \mathrm{wanted}$ to use fiber oplics for the uncreatsed distiunce and IMI/RIT benefits.

I Inforturitely. lie fiter optic techin)logy was not mature

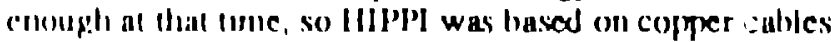
(1) mect the tume and simplicity poals. Fis is a follow-on

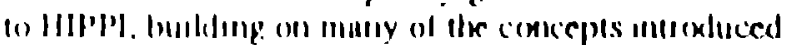
wilh IIIPly lic is also in ANSI Task (iroup X $\times 19.3$

While HIPly is mote ol a communications interface, lic was if temfed to also maliess the ined for a tasier I/C)

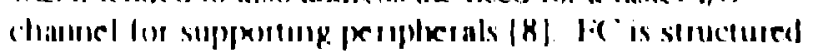

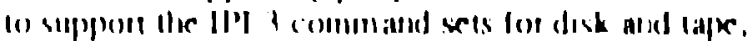

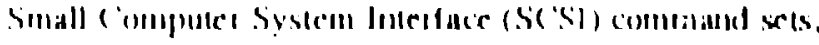

IBM S/370 Block Muluplexer commands, and HIPPI-FP' packets.

FC, like HIPPI, is also a point-to-point interface. but FC. is more general and suppors more types of transfers. FC is more of an "all things to all people" type of interfice. In the long run, FC will provide more capability than HIPPI, but its generality also produces more complexity, which in tum makes it harder to specify and implement. HIPPI could almost be built with Radio Shack pans. an effective FC implementation will require cusiom silicon

Where options were avoided in HIPPI, FC is full of options. For eximple, FC supports four speeds with data transfer rates of 12.5. 25, 50, and $100 \mathrm{MBytcs} / \mathrm{s}$, corresponding to $132,266,531$, and 1062.5 Mbaud serial signalling rates. The media may be single mode fiber or two sizes of mulrimode fiber, or even inexpensive copper coax cable for shon distances. Optical transmitters may be LEDs or lasers. Combinations of the above are specified for different speeds and distances.

HIPPI operates in a datagram mode where higher layer protocols worry about error recovery and retrizsmission. HIPPI also limits trausfers :o a single packet at a time. where the packet may be of any size. In contrast, FC suppors three classes of service:

Class 1 - Dedicated connection, guaranteed delivery, frames reccived in transmilted order

Class 2 - Frame swilched, buffer-to-buifer now control, guaranteed delivery, frames may he reordered, virtual connections

Class 3. Datagraus delivery and frame ordering nor guarartood

Class $I$ is seen as very useful for visualization, where a dedicated connection may exist for long periods of time. and interference from other dali strean:, is undesirable. C.ass 2 will probably be used heavily for Iradiuonal $1 / O$ Iransfers, where multiple Iransfers are open at one tume with frames fiom the different trarıslers multiplexed on a single fiter. Class 3 can be used with traditional communica'tons protocols where recovery and re-ondering. are alrearly hardled in ile upper layer protocols, and where conuecuon set-up times must be avoided.

IC is structured imo four layers for ease af undersianding. und documentation. I: $\left(^{\circ}, 0\right)$ specifies uke physical layer with the serial dri"ets, receivers. media, etc l' '- I

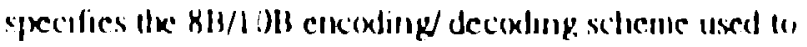

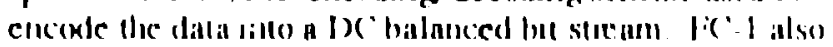

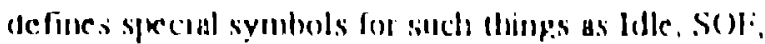

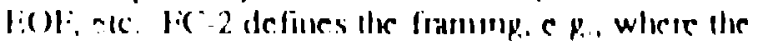
adderss, comtrol, data, und diect fields are lexilled mol whit

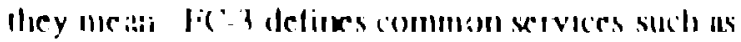

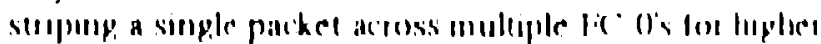

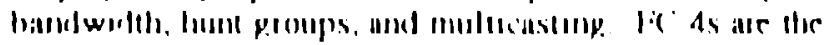


mappings to higher layer protocols, e.g., to the IPI-3 command sets for dist and tape.

The logical hierarchy within FC is:

- Operation - Logical construct to identify and group things for an upper layer protocol

- Exchange - Group of sequences, normally related to 1/O control blocks

- Sequence - Unidirectional group of frames

- Frame - Basic transfer unit, contains header with addresses, control, of KBytes of dats, basic flow control unit, contains checksum, words within a frame are synchronous

Identifier and offset fields are contained within each frame's header, allowing the receiving port to place the data in the proper place in memory, hopefully eliminating the need for data copies in the receiving computer. Considerable wort has gene into providing multiple levels of indirection so that the individual frames can be disposed of by state machines implemented in silicon rauler than having to be handled by a general purpose processor. The feeling is that this is mandatory if we are to keep up with the daca transfer rate. multiplexed frames, and the vanery of applications.

\section{NETWORK ARCHITECTURES}

HIPPI and FC provide point-to-point connections which can be used as the basic building blocks for computer networks. Different types of network architectures are appropnale for different applications. HIPPI and FC lend thenselves to ning and circuit switch architectures $|9|$.

\section{Circuit switch archifectures}

Ior comparison, cin'uit switching is what is used in the Iclephone system loday. That is, your call is separate and Irkependent fiom someone else's call, even Uhough you ure both usulng the saine circuit switch hardware. The separaic but uxleperkent nature of circust switching is one of the requirements for visualization. The Ios Alamos Naltonal l.alboratory is protolyping a circuil switchung alchutecture cilled) ile Multuple (iosshar Network [10)

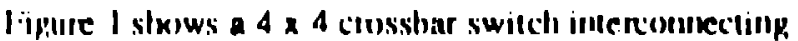
fout hosts Note that contecilons exist for simuleancouss

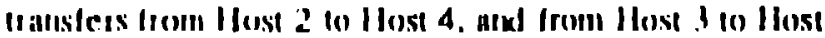

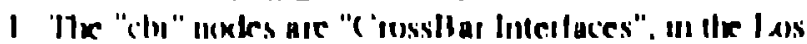
Alamos nonenclature 'They would perform such

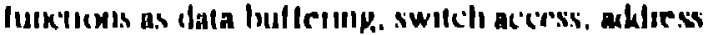
iesolutum, securily ('leckillk, and low level proticouls

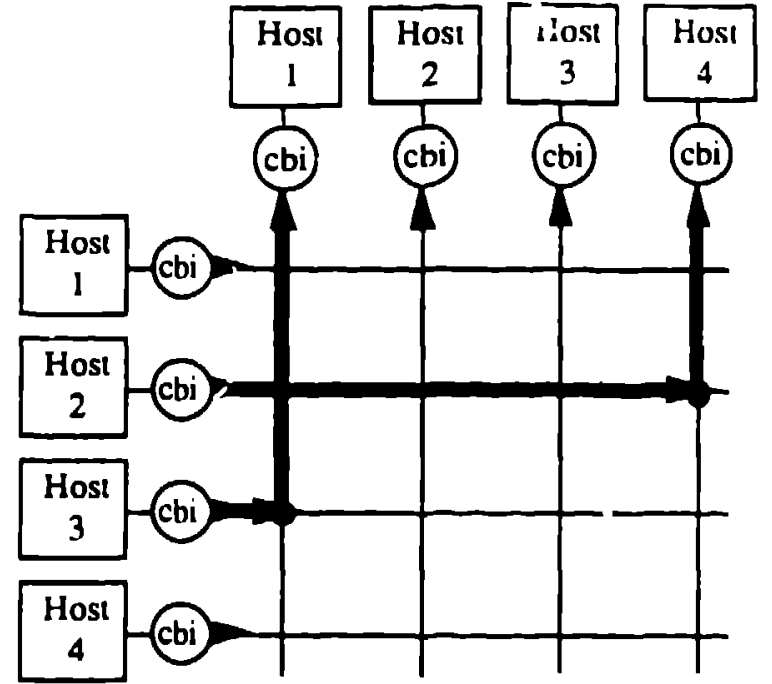

Figure 1. Circuil switch architecture

The circuit switch components run at the basic channel ratc. and obtain a thigh total bandwidth by allowing multiple channels to be aztive simultaneously. For example, an $8 \times 8$ circuit switch for HIPPI would have cach channel running a $800 \mathrm{Mbi} / \mathrm{s}$, llic circuits within the switch running at $800 \mathrm{Mbit} / \mathrm{s}$, and a tolal bandwidth of $6400 \mathrm{Mbit} / \mathrm{s}$. In use, one mainframe may be sending data to a visualization station, while another mainframe is reading dace from a disk system, with hots simultaneously transferring data at 800 Mbit/s rates.

Nomally, once a connection is completed, Uie channel operates as if there were no switch itivolved. That is. delays may uccur on circuit setup. but no Jelays. other than circuit delays. an encountered once the connection is completed.

Circuil swilc/les utilize different access control mechanisms from iraditional bus or rilly urchitectures. Nanely, if a source on a switch finds that its ircjucsted destimation is husy. and if Ure source las data for a Jiflerent destimation. then the source can try scikling to the second destmiltion. Will a bus or imp. il the media was busy, yen c'ould not send even if you had data for anoulari destination.

('amp)-(Bu features may also le used to hany a sounce waitup. Lor a specific desimalion lo c(minplete. ('all

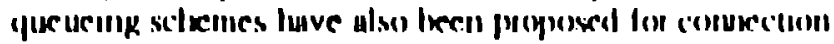
selups. Siwitch systems need to walch (hIt lol luulg cluanucls arol chanurl hogs.

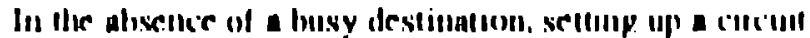

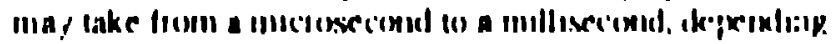

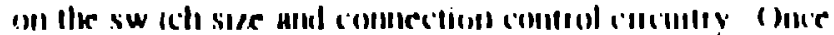

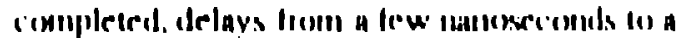

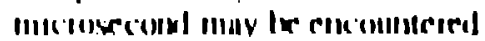


While a ring or bus system may grow indefinitely one attachment at a time, circuil switches grow in major increments. For example, if you are using an $8 \times 8$ switch and want 10 add a ninth element, then you have to buy another whole $8 \times 8$ switch and interconnect the switches. Switch architectures are ofien square. e.g." crossbars, but may be tailored to a variety of applications. For example, a local switch may interconnect several workstations but have only one connection to the main switch; supporting only one mainframe to workstacion transfer at a time.

There are, advantages to large switches, e.g., up to 4096 connections, and to small modular switches, e.g.. $8 \times 8$ or $32 \times 32$, and vendors are building both. Some of the early uses may give us some guidelines on the best way to apply switches.

\section{Ring architectıres}

Ring networks provide a single daca path that is shared by all of the attachments. This single data path limits the total bandwidth, but does give a natural broadcast capability. Bus access is usually determined by token passing or time slots. An advantage of rings is that it is usually fairl; casy to add one more station.

Figure 2 shows a ring network interconnecting four hosts. The "RI" elements are "ring interfaces" for performing such funcuons ts dala buffenng. ring access. data buffering, security clecking. and low level protocols.

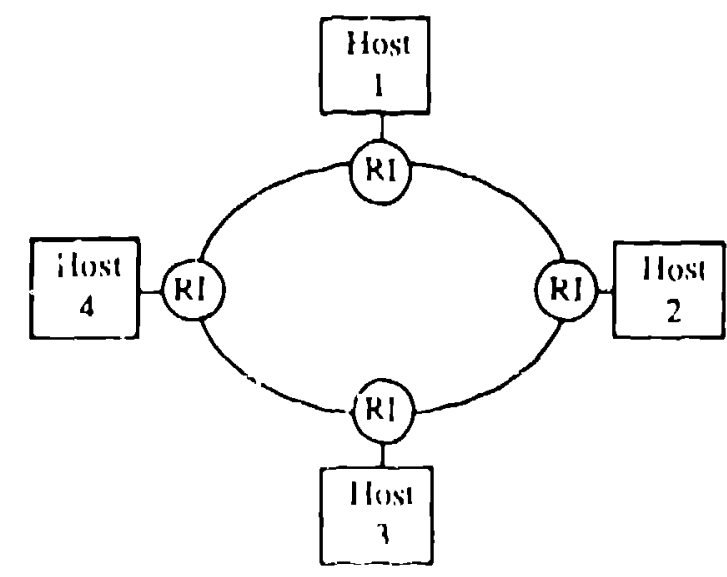

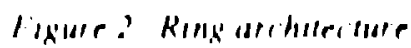

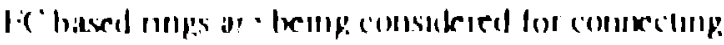

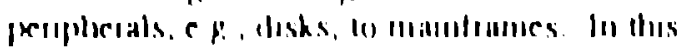

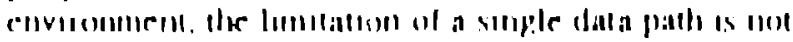

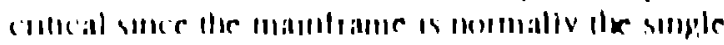

generator and user of the data. It is envisioned that thesc nngs would be cheaper thin a circuil swilch architecture.

Wavelength Division Multiplexing (WDM)

Wavelength division multiplexing (WDM) operates by sending muluple data streams, each at a separate wavelength (i.e., frequency), on a single fiber [11]. For comparison, FC uses baseband signalling, sending only a single stream down a fiber. WDM can be compared to the lead-in cable for your TV set; there is only one cable, but there are multiple station's signals on that cable.

Sending to a particular destination is accomplished by having the source and destination both use the same wavelength. To make this into a networt requires that either the source or destination be able to tune to specific wavelengths. Laboratory systems today operale with a few tens of stations. The problems that need to be solved to make WDM into a commercially viable computer network includs improved wavelength sensitivity, fasier swilching. and cheaper components [12]. High-definition TV to the home may well be the initial market for WDM. providing the components for economical computer networks of the future. With changes to acrommodate the access differences, I:C should work well with WDM.

\section{OPEN PROBLEMS REQUIRING FUTURE WORK}

IIIPPI and FC may be the lnwer layers of futurn network architectures. With these higher speed physical conrections, there i., itkentive 10 work on the nex! botteneck, which muy well be the Transpon Layer. TCPRP and T'PA ale :le most widely used transport layers, but tike may not pertorm well in the gigabit clivironment $[1, ?]$.

Previous protocols were designed to operate with yesterdays physical! yers. Now, ratlicr dian ertor rates of $10^{4}$. ciror tules of $10^{\circ}$ ure expected. The distances atal transiler rates also affect ile protocol. 'Ile delay hetween ('alifonia aid New Yoik is 30) mulliseconds, allowing $1(k)$ puckets of I Kliyies each lo le in transit. Window sires, llow conteol, arxl error iecouvery at the hipler specels ixed lo le whessued

Superempuless have peoven lo te very effective for

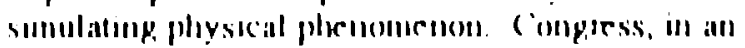

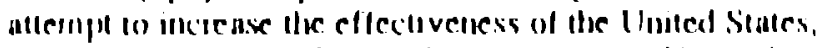
1. pushunp. и Nallomal Reseanch und Balucialion Nelwork (NRI:N), will a ponal of a colast 10 collst $10(0)$ () Mlolls

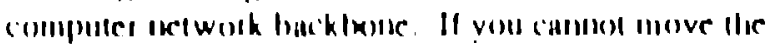
uses to the compule ts, llien make the computers 
available to the users as if they were adjacent. There is a lot of research and lesting going on to make the NREN a reality within the time trame goal.

Interoperability with the telephone switching systems is required to realize the NREN. The telecum '. istry has been promoung Asynchronous Transfer Moc: ATM) for switching and routing. ATM uses a basic cell size of 48 bytes plus a 5-byte header. ATM makes good sense when supporting many voice circuits, how well it works with gigabit/s data transfers remains to be seen.

\section{SUMMAR Y}

Computer networks operating at gigabit per second transfer rates are seen a: necessary for many applicauions, and gigabit networks are becoming available. HIPPI and FC will provide some of the basic building blocks for these networks. Further work needs to be done in higher layer protocols, and long distance nerworks, to achicve our national goals.

\section{HIBLIOGRAPHY}

(1) K. H. Winkler, M. L. Norman, and J. L. Nonton, "On the Characteristics of a Numerical Fluid Dynamics Simulator," Austin Symposium on Algorithms, Architectures. and the Future of Scienlific Compulation. March, 1985.

(2) F. E. Ross, "TDDI - A TuUnal," IEEE Commun Mas., vol. 24. Noveinler 1986, pp. 10-17.

13) High-Perfomance Parallel Interface - Mechanucal, Electrica! and Sipnalling Protoco! Specification

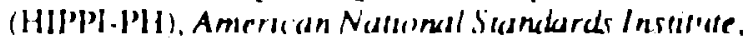
X.1.18.3-1041

(4) 1) E. Tolmue. "The High-Speed (hanunel (HSC)

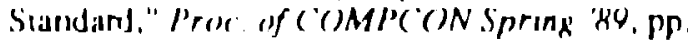
$.314-317$

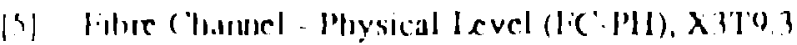
(1) $/ 1014$

[6] I cosllow, "Ihese days It's IIIIPl' to net

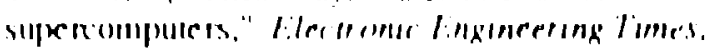

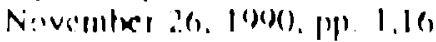

11) J Shandle. "(inpalut irets pet reiuly for itif-ofl,"

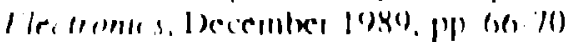

[8] R. Cummings, "New era s. ?wns for peripheral channels," Laser Focus World, Sepicmber 1990, pp. $165-174$.

[9] R. M. Grow. "Gigabit LAN Pancì Discussion," Proc. of 14 th Conference on Local Computer Nerworks, Minneapolis, Cctober, 1989, pp. 14-15.

[10] R. L. Hobelbeinricb, and R. G. Thomsen. "Muluple Crossbar Network: A Switched High-Speed Local Network.", Proc. of 14 ih Conference on Local Computer Nenworks, Minneapolis, October, 1989. pp. 285-291.

(11) N. R. Dono, P. E. Green, K. Liu, R. Ramaswami. and $F$. F. Tong, "Wavelength division multiple access networks for computer communication," IEEE Jour. Sel. Areas in Comm., vol 8, no. 6. 1990

[12] P. E. Green. "T:2 Future of Fiber Optic Computer Networks," COMPUTER, September, 1991.

[13] T. F. LaPona, M. Schwanz. "Architectures. Fcatures, and Implementalion of High-Speed Transpon Prolocols," IEEE Nelwork, vol 4, no. 2, May 1991, pp. 1A-22. 